http://doi.org/10.48195/sepe2021-011

\title{
VIVÊNCIA EXTENSIONISTA NA ODONTOPEDIATRIA: UM RELATO DE EXPERIÊNCIA
}

\author{
Nathalia Baldicera Lopes'; Kétlin Fagundes Teixeira²; Débora Dalpian; \\ Lenise Menezes Seerig ${ }^{4}$;
}

\section{RESUMO}

O presente trabalho visa a demonstração de um relato de experiência vivenciado na Clínica de Odontopediatria, durante o decorrer da disciplina extensionista de Ações Integradas em Odontologia III. A ferramenta metodológica utilizada no presente relato foi a Espiral Construtivista, proposta por Lima (2017). Será evidenciado no presente relato todos os sentimentos vividos durante o primeiro contato com crianças durante a graduação.

A Odontopediatria é uma área que exige, como qualquer área da odontologia, uma excelência técnica, mas ao mesmo tempo, é necessário o despertar de um sentimento ainda maior de carinho, empatia e sensibilidade, para que possamos nos conectar da melhor forma possível com nossos pacientes. Cada paciente é singular, cada um deles é capaz de despertar em nós, cirurgiões-dentistas, o poder da imaginação e do mágico. A Odontopediatria é única, pois nos faz mergulhar no mundo interior da cada um de nossos pacientes de uma forma diferenciada, em especial quando estamos tratando crianças mais vulneráveis e em risco social.

Palavras-chave: Extensão; Odontopediatria; Pesquisa.

Eixo Temático: Atenção Integral e Promoção à Saúde (AIPS)

\section{INTRODUÇÃO}

A extensão universitária engloba todas as atividades promovidas por instituições de ensino superior destinadas ao processo de interação entre a comunidade acadêmica e a sociedade em que ela está inserida. Essa interação com 
as localidades pode se dar por trabalhos contínuos realizados por alunos e professores que tem por objetivo a troca de conhecimentos. Também tem por objetivo atender as demandas e necessidades locais, principalmente voltadas para indivíduos com uma maior vulnerabilidade social, ao mesmo tempo em que respondem ao currículo de seus cursos e estimulam a autonomia entre os envolvidos, promovendo saúde e conhecimento. Os alunos que participam dessas atividades aprendem a estar mais próximos das necessidades, anseios e desejos da comunidade, ao mesmo tempo em que socializam e democratizam o conhecimento. De acordo com Alves et al. (2011, p. 231):

Devemos considerar o alcance do universo social que atinge um projeto de extensão que envolve: "criança e adulto - família e escola - e a comunidade", principalmente pelo esclarecimento, prevenção e erradicação da cárie dentária, bem como o amplo campo que se abre aos acadêmicos na integração Universidade - Comunidade. Também fortalece o processo da interdisciplinaridade, bem como o entrosamento com outras atividades comunitárias e sociais, graças ao contato direto com o meio o que permite a retro-alimentação obtida nas palestras dialogadas, em reuniões com a comunidade e trabalhando a própria realidade que resulta das necessidades manifestadas espontaneamente pela cidadania local, propiciando um processo de transformação, mesmo em longo prazo, da educação em saúde bucal tão necessária e urgente.

O objetivo geral da disciplina de Ações Integradas em Odontologia III é habilitar o acadêmico na realização de triagem de risco de cárie, diagnóstico das doenças bucais, plano de tratamento e procedimentos preventivos e curativos no paciente infantil e adolescente e; em grupos e atividades de promoção de saúde. Também tem por objetivo possibilitar o aprendizado como uma experiência baseada em humanização, diálogo, construção de vínculo, possibilidade de trocas e desenvolvimento da autonomia do cuidado.

Com foco na Odontopediatria que é uma especialidade dentro da odontologia voltada principalmente para cuidar da saúde bucal dos mais jovens, desde bebês até adolescentes. Dessa forma, o profissional da área tem como objetivo o diagnóstico, prevenção, tratamento e o controle dos problemas de saúde bucal do bebê, da criança 
e do adolescente, além da integração desses procedimentos com os demais profissionais da área da saúde.

A área da Odontopediatria representa um verdadeiro desafio na Odontologia. Todos os pacientes apresentam suas particularidades o que torna todas as consultas desafiantes. Atuar de forma tão próxima com crianças e adolescentes, batendo de frente com seus medos, angustias, dúvidas, sentimentos é de longe uma tarefa difícil que exige muita paciência e, também, muito carinho de quem a realiza.

Sendo aluno de Odontologia há sempre uma expectativa grande quanto a prática clínica odontopediátrica, sendo ela positiva ou negativa. Já é esperado que estejamos prontos para lidar com situações delicadas, por vezes estressantes, em que teremos que adquirir habilidades de manejo de comportamento, a fim de conduzir da maneira mais harmônica possível nossos atendimentos, pois estaremos lidando com seres humanos, frágeis, que também possuem medos, desejos e precisam ser respeitados.

Cada pessoa é singular na sua peculiaridade, é esperado que cada criança e cada adolescente tenha comportamentos totalmente diferentes e que exigirão a utilização de várias técnicas de manejo, desde um apenas "mostrar, falar, fazer" até uma "contenção física", e é exatamente nesse contexto único da prática clínica odontopediátrica que é colocado em jogo, não somente a atitude da criança, mas também as atitudes dos profissionais frente $a$ isso, o que torna cada consulta um novo desafio.

\section{METODOLOGIA}

Com base em uma vivência singular, de duas acadêmicas de odontologia frente à prática clínica na disciplina de Ações Integradas em Odontologia III, o presente relato visa descrever detalhadamente como a experiência foi vivenciada, dando enfoque para os procedimentos realizados, interface entre a expectativa, descrição do que foi observado, sentimentos, descobertas, dificuldades e reflexões. 
As atividades práticas foram desenvolvidas nos Laboratórios de Ensino de Práticas Odontológicas da UFN (clínicas), pelos alunos do $7^{0}$ semestre, com realização de procedimentos odontológicos de baixa a média complexidade. Foram realizadas abordagens a respeito da higiene bucal, adequação dos hábitos alimentares e ações de promoção de saúde envolvendo a propagação de informações de interesse da comunidade e melhoraria na qualidade de vida dos indivíduos participantes, incluindo o cuidado integrado. Também, foram realizados três procedimentos específicos nesse período de aprendizado: ART (Tratamento Restaurador Atraumático ), aplicação de Selante e Exodontia de Dentes Decíduos

Foi utilizada, como ferramenta metodológica na disciplina de Ações Integradas em Odontologia III, a Espiral Construtivista, proposta por Lima (2017), com proposta de identificar os problemas, formular explicações, elaborar questões, buscar novas informações, construir novos significados e avaliação do processo.

\section{RESULTADOS E DISCUSSÕES}

A expectativa para a disciplina foi muito próxima do que foi vivenciado. Já era esperado choros, medos, desconfortos, desafios, o que facilitou um pouco a vivência de fato. Porém, como sendo uma experiência totalmente nova, receios e medos aconteceram de ambas as partes, mas sempre buscando o acolhimento, o carinho, 0 conforto para com a criança. As crianças e adolescentes foram tratados com todo respeito e carinho que merecem, como seres humanos únicos e especiais.

Na prática foi observado o medo do desconhecido. Por vezes não fazemos ideia do quanto certas situações podem ser desafiantes para os pequenos também. Uma simples radiografia com posicionador causou lágrimas e muito medo na nossa primeira paciente, algo simples para nós, mas desconhecido para eles. O medo dos objetos, o medo do que está sendo feito, mesmo tendo a certeza que não existe dor, a criança se mostra assustada pelo simples fato de não saber de fato o que está acontecendo, ou seja, a simples ausência de dor não significa ausência de medo. Essa conclusão é algo que se confirma muito no mundo das crianças e foi possível 
perceber, principalmente, após a extração de dois dentinhos decíduos de uma de nossas pacientes, em que era garantido que ela não estava sentindo dor, mas sempre que nos aproximávamos com o instrumental, o simples fato dela saber que estava acontecendo algo diferente, já era interpretado como "dor". Além disso, as crianças são atraídas por todas as informações ao redor delas, o ambiente faz toda a diferença no atendimento, um local de atendimento acolhedor e lúdico, que traga um pouco de distração e conforto para a criança, já faz toda a diferença para elas. É importante que o local traga informações que estejam ligadas ao cotidiano, desenhos, brinquedos e cores. Essa é uma parte que difere muito no atendimento com adultos, por exemplo.

Todas as sensações são captadas por eles, o simples choro de outra criança no box ao lado já é uma sensação de terror para outra criança e vice-versa. A dúvida deles quanto ao que vai acontecer, o pânico de ver uma Carpule e se assustar, por não entender que aquela "injeção" é o que vai garantir que a tão temida "dor" não aconteça. O pânico de qualquer objeto que transpareça uma ideia de "dor", tudo para eles é um imenso desconhecido, do mais simples ao mais complexo. E frente a toda essa imensidão de sensações está nós, Cirurgiões-Dentistas, com um papel de trazer alívio, mas também um pouco de pânico, de sermos os super-heróis, mas, ás vezes, um pouco vilões, aos olhos deles. Essa mistura de papéis trouxe uma sensação de capacidade, responsabilidade e orgulho. É uma sensação única saber que somos capazes de trazer um bem-estar maior para a vida daquele paciente, mesmo após alguns minutos de pânico e, saber dar nosso melhor, saber que por um momento somos responsáveis por um filho ou uma filha de um pai ou de uma mãe, uma preciosidade que foi confiada a nós. Neste momento fazemos a diferença em como aquele ser humano vai ter na sua mente o papel de um dentista super-herói e não um vilão. Tudo isso depende apenas do nosso manejo frente a situações que são, de fato, muito desafiadoras. As nossas ações vão ficar marcadas para sempre no imaginário de cada criança e isso é uma grande responsabilidade.

É sempre um desafio, se quem diz que a Odontopediatria não gera descobertas e dificuldades diárias, mentiu. Nunca é uma tarefa fácil lidar com sentimentos de seres 
humanos tão únicos e frágeis. Todos os dias são desafiantes, todos os dias são novas descobertas e dificuldades, pois cada paciente é singular.

A experiência vivida na clínica durante as semanas de aprendizado superam todos os aspectos da teoria. Tudo que é teórico parece mais simples do que quando temos que pôr em prática. Na teoria sabemos quais técnicas de manejo de comportamento existem, mas na prática um "falar, mostrar, fazer" pode não ser tão simples quanto parece ou na teoria sabemos que a criança tem medo de dentista e que pode chorar, mas na prática o desespero toma conta. A teoria é limitada, necessária, mas limitada, pois nada supera nossa reação frente a situações reais. $\mathrm{Na}$ Odontopediatria, não somente lidamos com a experiência técnica dos procedimentos, não somente com as dúvidas: "será que conseguirei extrair o dente decíduo?", "será que consigo fazer a ART?", mas também lidamos com "e se a criança não abrir a boca?”, “ e o choro? Desespero? Gritos? “, " eu sou capaz de realizar aquele procedimento em condições tão desafiadoras?". Esse é o ponto da Odontopediatria. É isso que a torna única. E é toda essa imensidão de sentimentos que despertam em nós um olhar, um carinho e um respeito por essa área tão especial.

A disciplina de Ações Integradas III nos possibilitou o primeiro encontro entre acadêmicos e crianças, mas também nos possibilitou o conhecimento do modo de vida dessas crianças, onde a grande maioria delas se encontravam em situação de vulnerabilidade social. É nesse momento que temos a chance de mergulhar em um novo cenário de vida, algo que pode ser assustador e diferente para nós. Muitas dessas crianças não possuem acesso a escovas de dentes individuais, dividindo-as com os irmãos ou acesso a creme dental, fio dental e até mesmo água fluoretada. $\mathrm{Na}$ nossa prática, a mãe de uma de nossas pacientes relatou que estava sem acesso a gás de cozinha havia um mês o que ocasionava em uma alimentação precária para suas filhas, algo que repercutiu diretamente na saúde bucal delas. Nesse contexto, surge esse novo desafio, promover saúde e adequar a saúde bucal de crianças que, muitas vezes, não tem acesso a itens fundamentais de higiene bucal ou em que não conseguem ter uma alimentação adequada. Esses momentos foram muito marcantes, 
são situações que nos geram surpresa e por vezes dor. Mas sabermos que podemos fazer a diferença para essas crianças é o que nos faz continuar, é ver o olhar brilhante da criança ao receber de presente uma escovinha de dentes e um creme dental, isso faz tudo valer mais a pena.

\section{CONCLUSÃO}

Chegando ao fim nosso último contato com a disciplina de Ações Integradas em Odontologia e finalizando a Odontopediatria com muito orgulho e gratidão. A disciplina foi aproveitada da melhor forma possível, sempre tentando tirar o máximo de proveito de todas as situações, como forma de obter o melhor conhecimento e habilidade. Despeço-me da disciplina de Ações Integradas em Odontologia III com a certeza de "dever cumprido" e um carinho muito grande pela Odontopediatria. Levaremos dessa experiência um grande conhecimento, que acredito se tornou algo essencial para nossa futura profissão. Conseguimos absorver a teoria e a prática da melhor maneira possível. A Odontopediatria nos trouxe muitos desafios, mas conseguimos passar por eles e hoje nos sentimos prontas para seguir nas novas etapas. Tivemos a oportunidade de a cada atendimento superar nossas limitações e termos a certeza que demos nosso melhor, ainda existe muito o que melhorar, mas acreditamos que estamos no caminho certo.

\section{REFERÊNCIAS}

ALVES, F. B. T.; GREGOL, L. R. G.; CZLUSNIAK, G. D.; JIMÉNEZ, E. E. O.; AÇÃO INTEGRADA EM ODONTOLOGIA NA COMUNIDADE: UMA EXPERIÊNCIA DA INTEGRAÇÃO ENSINO/EXTENSÃO. Revista Conexão da UEPG, Ponto Grossa, v. 7, n. 2, pp.230-239, Jul./Dez. 2011.

LIMA, V.V. Espiral construtivista: uma metodologia ativa de ensinoaprendizagem. Revista Interface (Botucatu), São Paulo, v. 21, n. 61, pp.421-434, Abr./Jun. 2017. 
EDUCAÇÃO, SAÚDE

ETECNOLOGIA

26 A 28 DE OUTUBRO DE 2021

\section{UFN}

